\title{
Purpose in Life as a System That Creates and Sustains Health and Well-Being: An Integrative, Testable Theory
}

\author{
Patrick E. McKnight and Todd B. Kashdan \\ George Mason University
}

\begin{abstract}
Purpose - a cognitive process that defines life goals and provides personal meaning-may help explain disparate empirical social science findings. Devoting effort and making progress toward life goals provides a significant, renewable source of engagement and meaning. Purpose offers a testable, causal system that synthesizes outcomes including life expectancy, satisfaction, and mental and physical health These outcomes may be explained best by considering the motivation of the individual - a motivation that comes from having a purpose. We provide a detailed definition with specific hypotheses derived from a synthesis of relevant findings from social, behavioral, biological, and cognitive literatures. To illustrate the uniqueness of the purpose model, we compared purpose with competing contemporary models that offer similar predictions. Addressing the structural features unique to purpose opens opportunities to build upon existing causal models of "how and why" health and well-being develop and change over time.
\end{abstract}

What do volunteer services, social support, pet care, and religious attendance have in common? Recent studies indicate that people participating in these activities live longer than those who do not. Volunteers had a $60 \%$ lower mortality rate compared with nonvolunteers (Oman, Thoresen, \& McMahon, 1999). Providers of social support had a $50 \%$ lower mortality rate than those who neither received nor provided social support (S. Brown, Nesse, Vinokur, \& Smith, 2003). Hypertensive people who owned pets had lower blood pressure and lived longer, as compared with non-pet owners (Allen, Shykoff, \& Izzo, 2001). Finally, frequent religious service attendees had longer lifespans compared with nonattendees or infrequent attendees (Strawbridge, Cohen, Shema, \& Kaplan, 1997). What these findings have in common appears to be longevity; however, purpose may link these behaviors. We hypothesize that purpose leads to longer life span, fewer health care problems, and greater life satisfaction. Purpose, from our perspective, is not something merely to attain, but rather is an important predictive variable of physical health and mental health. Furthermore, our conceptualization of purpose does not rule out other routes to healthy living. However, when present, purpose is central to a person's life narrative. Neglecting its presence can lead to erroneous conclusions about "how" and "why" people behave as they do.

\section{What Is Purpose?}

Purpose is a central, self-organizing life aim that organizes and stimulates goals, manages behaviors, and provides a sense of meaning. Purpose directs life goals and daily decisions by guiding the use of finite personal resources. Instead of governing behavior,

Patrick E. McKnight and Todd B. Kashdan, Department of Psychology, George Mason University.

Correspondence concerning this article should be addressed to Patrick E. McKnight, Department of Psychology, George Mason University, MSN 3F5, 4400 University Drive, Fairfax, VA 22030-4444. E-mail:pmcknigh@gmu.edu purpose offers direction just as a compass offers direction to a navigator; following that compass (i.e., purpose) is optional. Living in accord with one's purpose, however, offers that person a self-sustaining source of meaning through goal pursuit and goal attainment. Furthermore, purpose is woven into a person's identity and behavior as a central, predominant theme-central to personality as well.

Purpose, therefore, helps organize several areas of research (e.g., meaning and goals) across many disciplines (e.g., social, behavioral, biological, and cognitive science). Our intent here is to provide a fuller explanation of a relatively neglected, relevant mechanism for longevity, general health, and well-being. Unlike other mechanisms that are important contributors to healthy living such as supportive social relationships (House, Landis, \& Umberson, 1988), positive affect (Cohen \& Pressman, 2006), optimism and hope (Segerstrom, 2005), and self-determined pursuits (Deci \& Ryan, 2000), purpose is contingent on the existence of a clearly defined mechanism that people devote effortful advances toward (i.e., appetitive). The presence of a purpose is expected to lead to greater persistence than other important life goals because a central, self-organizing life aim resonates across time and context.

\section{Differentiating Purpose From Religiosity and Meaning}

The concept of purpose exists in both the lay and social science literatures as either religiosity (Warren, 2002), spirituality (R. Emmons, 1999) or meaning (King, Hicks, Krull, \& Del Gaiso, 2006; Klinger, 1977; Wong \& Fry, 1998; Steger, Frazier, Oishi, \& Kaler, 2006).

Common among these perspectives is personal agency (Frankl, 1963; deCharms, 1968) - a view of behavioral action (Carver \& White, 1994) and attribution (Vallerand, Deci, \& Ryan, 1987)that we hold as central to purpose as well. These perspectives differ in many ways from purpose. First, purpose is not essential to well-being as suggested by Frankl (1963) and Warren (2002). Frankl's perspective is that personal agency is an essential determinant of mental and physical health that can be changed (e.g., via therapeutic means or "logotherapy"); religious faiths typically hold 
that same perspective. A person may be healthy for genetic reasons that have nothing to do with personal agency or purpose. Second, religious faith (Warren, 2002) is not necessary for purpose. Purpose, in the religious or spiritual sense, serves as an outcome of faith. Those who have faith reap gains by acting in accord with religious/spiritual teachings to reach some desirable end (e.g., eternal salvation). Purpose may come from other nonfaith basessuch as goodwill toward others-and exert a powerful influence on a person's life. Third, purpose gives a person a sense of meaning that may not always be recognizable nor easily articulated. Selfreport measures probably miss what we mean by purpose because many people may label or associate their behaviors as purposeful.

Fourth, purpose may not necessarily be available to every person. There are individual differences (e.g., cognitive ability) that likely limit purpose formation. A person who is unable to grasp abstract concepts might find it difficult to generate a purpose since purpose requires insight, introspection, and planning (Carver \& Scheier, 2002). General cognitive ability may be altered not just by inherited general intelligence, but also by injury (e.g., traumatic brain injury), disease (e.g., dementia), or neglect (e.g., Korsakoff's syndrome brought on by alcoholism). Finally, purpose is not a mere product of faith, meaning, or personal agency. Meaning does not always drive purpose; rather, meaning probably drives the development of purpose. Once a purpose becomes developed, purpose drives meaning. In short, purpose and meaning have a temporal, bidirectional relationship. When these faith-based or meaning-focused approaches move beyond processing and interpreting reality to explicitly acknowledge motivated planning and acting, they begin to offer what we refer to as purpose. Purpose shares several common threads with these other approaches including personal agency, prioritizing goal-relevant behaviors, and goal setting.

\section{Differentiating Purpose From Goals}

Purpose and goals are not synonymous. Goals are more precise in their influence of proximal behaviors (Carver \& Scheier, 1998). "Goals focus on a specific cognitively represented endpoint and serve to guide the individual's behavior toward or away from that end point" (Elliot, 2006, p. 113). Purpose provides a broader motivational component that stimulates goals and influences behavior. Purpose does not necessitate a designated outcome to be attained, but it must motivate the person to be goal oriented. Elliot (2006) further clarified the role of goals in the motivation process by excluding the hierarchical influence we ascribe to purpose. Reasonable goals have terminal outcomes; purposes, like values, do not have necessary terminal outcomes (Wilson \& Murrell, 2004a).

Goals can serve as an organizing framework for other subgoals (Elliot, Gable, \& Mapes, 2006). Similarly, purpose stimulates many smaller, consistent goals. Some might argue that purpose, from this standpoint, merely represents a higher-order goal that stimulates lower-order goals (cf. hierarchical goal structures; Carver \& Scheier, 1998). Purpose drives the higher-order goals from our perspective. Once a person satisfies a higher-order goal, another goal that is logically consistent with the purpose becomes relevant and stimulates the production of other logically consistent lower-order goals. Thus, purpose becomes the supraordinate goal manager.
Both higher-order and lower-order goals come from a purpose. We expect that people who have a purpose in life would move seamlessly from goal to goal or manage multiple goals simultaneously. Conversely, a person without purpose may achieve a goal but after that achievement find it difficult to readily identify another goal. Goals, therefore, are central to and are produced by purpose.

"Goals provide a sense of meaning and purpose in life" ( $R$. Emmons, 1999, pp. 3). We hold that purpose works in the opposite causal direction by causing well-formed, organized goal structures and meaning. Simply having a goal will not necessarily indicate a purpose. People may have an extensive hierarchy of goals; that hierarchy does not mean that the person has a purpose either. At a single point in time, goals that are higher in the hierarchy offer an adequate, temporally dependent indicator of a person's identity. Understanding the totality of a person or what motivates them to do what they do across time and context (i.e., a person's life narrative; McAdams, 2001) requires an even higher level construct. Given these features, one person's purpose cannot be another person's goal. Purpose is at the highest level of analysis and provides some degree of centrality in a person's identity; the same cannot be said for goals.

Our perspective on purpose is consistent with behavioral congruence models of personality that suggest people derive the greatest positive experiences when they participate in activities congruent with their habits and predispositions (i.e., dominant personality traits) and the least pleasure when there is discord (Côté \& Moskowitz, 1998; Lyubomirsky et al., 2005; Sheldon \& Kasser, 1998). In addition, goal self-concordance refers to the degree to which goal pursuits are congruent with intrinsic values and dominant behavior tendencies. Numerous studies have demonstrated that people make better progress toward their goals (e.g., Sheldon \& Elliot, 1999), show greater psychological health (e.g., Kasser \& Ryan, 1993), and display more cognitive flexibility and depth of processing (e.g., Grolnick \& Ryan, 1987), when their actions are self-determined and fit with dominant traits. We believe that our model is an extension of this work by postulating a latent underlying factor that increases the strength and consistency of behavioral congruence, goal self-concordance, and other psychological processes and assumptions that account for well-studied relations in various life domains.

\section{Further Clarifications}

\section{Three Dimensions of Purpose}

Our previous discussion may suggest that purpose is a binary condition where a person either has a purpose or does not. Instead, purpose lies along a three-dimensional continuum-scope, strength, and awareness. Scope refers to how ubiquitous the purpose is in a person's life. A purpose that is central to the person's life and influences all actions, thoughts, and emotions ought to be considered to have a broad scope. Scope dictates the extent the purpose influences action under different contexts and conditions. To an extent, scope may dictate organization and context sensitivity. A purpose with a broad scope will be less organized but also influence a greater range of behaviors across a wider context (for work on personality integration, see Rogers, 1951; Sheldon \& Kasser, 1995). 
Strength may be described best as the tendency for the purpose to influence the actions, thoughts, and emotions in the domains that are relevant to its scope. A strong purpose is one that powerfully influences purpose relevant behaviors. Scope and strength dictate the extent to which the purpose influences longevity, health, and well-being. A purpose characterized by broad scope and great strength ought to have a more pronounced effect on those outcomes. Thus, the more central a purpose is in a person's life and the more that purpose influences the actions, thoughts, and emotions of that person, the more likely that person will benefit from having that purpose. Moreover, a broad, strong purpose will bring about resiliency to obstacles (for evidence to support a similar synergistic model, see Koestner, Lekes, Powers, \& Chicoine, 2002). People without structural frameworks to integrate and organize goals display lower levels of health and well-being (Donahue, Robins, Roberts, \& John, 1993; R. A. Emmons, 1991). Scope and strength lead to stronger structural frameworks.

Scope and strength are orthogonal descriptors; although it might be easy to imagine these qualities being related for most people. A person may have a single purpose that is both broad in scope and strong in influence. However, there is no reason to suspect that a person will likely have that type of purpose rather than some other combination of scope and strength. Perhaps a more realistic expectation is that the average person will have multiple, small scope purposes that are all relatively weak influences on behavior.

Finally, awareness (i.e., the "contents of consciousness" explored by Gray, 1995; Jackendoff, 1987) reflects the extent to which a person is aware and can articulate her purpose. A person may be aware of a purpose to the extent that the purpose is available and salient. Additionally, scope and strength influence awareness. Consider a simple analogy of gravity. The force of gravity on earth is all-encompassing (broad in scope), but weak. We go about our daily lives without paying much attention to gravitational forces. If, however, we were instantly transported to Jupiter-a planet with twice earth's gravitational force-our awareness of gravity would increase substantially. Simply put, a purpose that is both broad in scope and strong in influence ought to be available to the person. Purpose consistent behaviors can be activated and can provide motivation for action outside of conscious awareness. People can be unknowingly influenced by information when it is incidentally activated by meaningful environmental and internal cues. "Nonconscious" influence appears to be particularly strong when the cues are relevant to goals that are highly integrated into the self (such as those derived from a purpose) (Bargh \& Barndollar, 1996; Kruglanski et al., 2002). Researchers have shown that people primed with information about personally relevant goals experienced greater well-being and progress toward those goals compared with people with fragmented goals (Burton, Lydon, D’Alessandro, \& Koestner, 2006). Additionally, people in the midst of goal pursuit automatically evaluated goal-relevant stimuli as being more positive than goalirrelevant stimuli (Ferguson \& Bargh, 2004); no such effects were found for people who already accomplished their goals.

Scope and strength relate to awareness in both obvious and subtle ways. We suspect that people with a strong purpose possess vast, interconnected networks of memories, emotions, and behaviors; this process represents the cognitive component of the architectural framework (e.g., Nelson \& Fivush, 2004). The memories integrated into this network include a broad range of environmental and internal cues relating to one's purpose, intermediate goals derived from that purpose, behaviors reflecting the implementation and pursuit of these goals, internal thoughts and feelings associated with purpose congruent activity, and the meaning associated with each of these elements. When one of these elements is activated, the rest of the network can become activated. For example, a person with a religious-based purpose viewing a sacred artifact may activate all the memories of religious activities, historical events, or feelings associated with being religious (for related findings, see Hicks \& King, 2008). The individual elements in this network can be activated in a relatively effortless manner and their interconnectedness allows them to constantly reinforce and reactivate one another. Scope and strength, therefore, relate to awareness by influencing the cognitive load.

Awareness decreases cognitive load by integrating motivation and behavior into a person's cognitive architectural framework. We do not mean to imply that the integration is complete and thus a habit. Instead, awareness provides the person with a vast connection of related, context-sensitive, behavioral tendencies. The connections are stochastic rather than deterministic by nature, thus allowing the person to shift among many behavioral tendencies with relative ease.

When a person is not aware of a purpose but still influenced by that purpose, there exists greater cognitive load and less efficient resource allocation (i.e., the distribution of resources such as energy and time to a given task). The person requires more time and effort to sort through the various behavioral options in each context. When a person is aware of a purpose, that purpose will likely be triggered by many environmental contingencies and pursuing the purpose requires less effort. Therefore, awareness influences both behavioral flexibility and efficient resource allocation.

Awareness may also increase the strength between purpose and the positive outcomes such as health and well-being (for a review of indirect support, see K. Brown, Ryan, \& Creswell, 2007).

\section{Pursuing Multiple Purposes}

A person may have multiple purposes with each in entirely different domains and each completely independent of other purposes. Multiple purposes may be beneficial to a point, but after that point only serve to reduce the resources for any single purpose. For example, a person who pursues a single purpose may become disheartened if the obstacles become too great to overcome. If that same person had several purposes-each within different domains - then she may shift from the currently impeded purpose to other more feasible purposes. Shifting between purposes facilitates the ongoing pursuit of purposeful living and thus may increase the positive benefits that result. Too many purposes, however, may lead to constant switching between purposes and never lead to any progress. Thus, the dilution of effort may reduce the positive benefits we ascribe to purpose (Zhang, Fishbach, \& Kruglanski, 2007). The problem addressed by multiple purposes is one of sustainability balanced by the pull of efficient resource allocation. 


\section{Value Judgments of Purpose}

We believe that there is minimal utility in designating a purpose as "good" or "bad" without defining social conditions that support or hinder their pursuit. A purpose that is consistent with wellestablished social values tends to produce intermediate goals that become easier to accomplish over time (Triandis, 1989). Even though there may be intermittent conflict with external forces (e.g., antagonistic people), goal-related progress and achievement is generally facilitated and rewarded by society. In contrast, purposes inconsistent with social values ought to produce intermediate goals that become more and more difficult to achieve because social forces actively thwart their achievement. Moreover, the cultural violations and sanctions increase with each successive goal. A person's purpose may not necessarily be socially acceptable, but we expect a different outcome over time for purposes that run contrary to social norms. Thus, social acceptance of purposes likely affects the person who lives for the purpose by imposing or reducing barriers. When barriers are increased, we expect people to experience far greater stress when pursuing a purpose. Those without a purpose might find other activities or pursuits to satisfy them if the resistance gets too great (Segerstrom, 2005). What separates those with purpose is the increased stress but the willingness to persist toward that purpose (recently referred to as grit; Duckworth, Peterson, Matthews, \& Kelly, 2007).

\section{The Science of Purpose}

As supportive evidence for the different aspects of purpose, we turn to related theories in social psychology, cognitive neuroscience, evolutionary theory, psychoneuroimmunology, and economics. The following review is not meant to be exhaustive but rather an empirical background that supports our description of purpose, underlying mechanisms, and consequences for the individual.

\section{Purpose in Social Psychology}

Purpose might be difficult to disentangle from existing motivational theories. By contrasting purpose with self-determination theory (SDT; Deci \& Ryan, 2000) and terror management theory (TMT; Greenberg, Pyszczynski, \& Solomon, 1986) we make a case for incremental validity. SDT suggests that satisfying feelings of autonomy, competence, and relatedness are essential to facilitate personal development and psychological well-being (Deci \& Ryan, 2000, p. 228). Additionally, SDT helps explain why personal strivings may have differential influences on well-being. The benefits of striving are compromised when a person feels controlled by external or internal pressures (e.g., caregiver wishes, guilt), ill-equipped to be successful, or unsupported by others (Assor, Roth, \& Deci, 2004; Gagn, 2003; Sheldon \& Krieger, 2007). Despite potential overlap between purpose and SDT, we do not believe purpose is reducible to manifest indicators of wellbeing. Working toward strivings congruent with central values has been shown to be the most successful route to enhancing well-being (Koestner et al., 2002; Sheldon, 2002). When strivings are selfselected and well-integrated with a person's preferences or personality traits (Sheldon, Ryan, Deci, \& Kasser, 2004; McGregor \& Little, 1998), the opportunity for substantial benefits are increased.
When strivings come from a central life aim, become a person's identity, and manifest in a person's routine behaviors, then SDT moves closer to our notion of purpose.

Many SDT researchers refer to self-concordant strivings as the optimal framework for pursuing desired life aims. Self-concordant strivings are defined as the "extent to which people pursue their set of personal goals with intrinsic interest and identity congruence rather than with feelings of introjected guilt and external compulsion" (Sheldon \& Kasser, 2001, p. 153). From this operational definition, it is assumed that these strivings are linked to people's central, enduring interests and values (Sheldon \& Elliot, 1999). However, this assumption has not been measured or studied. What has been assessed is the degree to which strivings are intrinsically motivated and self-determined. We argue that the explicit connection to core values and the centrality of strivings to a person's identity characterize the elements of what we are describing as purpose. In our view, all variants of purpose are self-concordant strivings but most self-concordant strivings do not reflect a purpose.

In contrast to SDT, TMT provides a different motivational framework that focuses on the inevitability of death. Attempts to cope with this existential dread leads to an indulgence in dominant cultural ideas, symbols, and behaviors to ward off anxiety (Solomon, Greenberg, \& Pyszczynski, 1991). In this model, people develop and pursue goals, meaning, and growth opportunities to avoid death-related anxiety. When the threat of death is salient, people respond by adapting safe, cultural world views. This is a theoretically rich framework and a number of creative experiments ruled out alternative explanations (e.g., Pyszczynski, Greenberg, Solomon, Arndt, \& Schimel, 2004). However, a number of critics (e.g., Muraven \& Baumeister, 1997; Ryan \& Deci, 2004; Snyder, 1997) argue that the comprehensiveness of the model is also a weakness, and priming mortality in college students with brief laboratory stimuli may not be applicable to how people act in everyday life.

It is hard to argue against the importance of self-preservation as a fundamental human motivation. Yet, suggesting that all other motivations stem from anxiety avoidance may go too far. People often focus on other issues while experiencing anxiety; the response ranges from acceptance to avoidance (S. Hayes, Follette, \& Linehan, 2004). Furthermore, it is unlikely that human beings exhibit a continual stream of nonconscious awareness of mortality that guides everyday behavior. In the advent of work suggesting that approach and avoidance motives are relatively independent at psychological, social, and biological levels of analysis, TMT proponents concluded that defensive protection against anxiety cannot fully account for growth-oriented processes, purpose in life, and well-being (Pyszczynski et al., 2004). Recent evidence suggests that mindfully aware individuals fail to show defensive reactions to deathrelated thoughts and feelings, such that TMT is less relevant to this subset of the population (Niemic et al., n.d.). As data are collected in the context of naturalistic environments over time, we will gain a better understanding of which set of circumstances, and for whom, is TMT effective at understanding day-to-day motivation and behavioral tendencies. To date, it is unclear how long TMT effects linger and whether insights are gained into purpose-related planning, persistence, progress, and benefits.

Purpose does not seem to be reducible to either SDT or TMT. The development and pursuit of purpose can certainly be 
influenced by the ingredients inherent to SDT or TMT but until evidence suggests otherwise, we are proponents of equifinalitypurpose can be the end state of numerous motivations and developmental pathways. As discussed previously, we also do not believe purpose is reducible to other singular motives such as needs. The inclusion of purposeful living as an explanatory variable in facilitating particular actions is best viewed as a complement in the hierarchical structure of self-regulation and personality (for a similar viewpoint, see Little, Salemla-Aro, \& Phillips, 2007). Lastly, we emphasize that purpose offers an incremental contribution to both SDT and TMT. Both SDT and TMT probably offer better short-term, proximal predictions, as compared with our theory of purpose. Those proximal predictions, however, may be accounted by purpose if all contingencies were known. Purpose may be a broader theoretical perspective that adds to predictions of how a person will view her life in the broadest context possible as opposed to any single time point (McAdams, 2001). Thus, the incremental contribution is one of scope and, perhaps, magnitude in prediction.

\section{Purpose in Evolution}

Scientific inquiry may be broadened into evolutionary theory where work on efficient resource allocation (Cichon, 1997, 2001) offers a simple explanatory mechanism for longevity. Resource allocation involves the distribution of scarce resources (e.g., energy) to important processes. Organisms thrive when they adapt to changing environmental conditions and perish when they fail to adapt. Resource allocation serves as one mechanism for adapting to changing environmental conditions. Purpose may provide the causal force for efficient resource allocation; people living with a purpose tend to shift resources (i.e., physical, biochemical, neural, and cognitive) according to the greatest need. Those who have the ability to use resources efficiently tend to be most adaptive and have the greatest longevity. People motivated by a purpose ought to be more efficient resource allocators and thus avoid environmental conditions that inhibit purpose-motivated behavior. The efficient resource allocator diverts energy-in the broadest sense-away from barriers toward alternative solutions.

\section{Purpose in Behavioral Economics}

Optimal resource allocation may be manifested in economic behavior. In particular, we hypothesize that through the appetitive process of purposeful living, an individual becomes a more efficient resource allocator with time and energy. That efficiency may not merely be a biological or physiological mechanism but rather an overarching process that governs many facets of behavior such as economic effort. Efficient resource allocation from an economist's standpoint may parallel David Ricardo's (1817) theory of comparative advantage with nations. Ricardo's theory stipulates that optimal resource allocation comes from a country producing goods that are most efficiently produced by that country and importing goods that are most efficiently produced elsewhere. Comparative advantage is simply a means by which nations were hypothesized to be more economically more efficient. The theory applies to individual action just as it applies to nations. Ricardo's theory applies to decision models and action efficiency (Shafir, Osherson, \& Smith, 1993), models of power over others (Tanaka,
1989), optimized personnel selection (Novick \& Ellis, 1977), and decision outcomes (Baron \& Kemp, 2004).

People motivated by purpose ought to act in ways consistent with efficient economic resource allocation. That is, those people will take on the tasks that they can do, and do better than others, while delegating tasks that are more easily accomplished by others. Purpose, therefore, may be a manager's most powerful tool to get workers to operate at peak efficiency.

The Marine Corps and coaches already know the power of purpose when it comes to efficient individual effort. Marines are taught a priority of values that dictate action- "God, country, and the Corps." These priorities give purpose and meaning to all actions. Additionally, Marines are trained to work as a team with a common purpose, but their individual actions are to be circumscribed to their specific specialty. Doing another Marine's job is a dereliction of duty; efficient action is essential to the success of the Corps. The reason why Ricardo's theory is relevant to our discussion is that efficiency may be the most important indicator of purposeful living (Gollwitzer, 1999) and economics broadens the scope of efficiency beyond just the evolutionary context into realm of everyday behaviors.

\section{Purpose in Psychoneuroimmunology}

Optimal resource allocation may also pertain to immune functioning; purpose ought to serve as a buffer in stressful times. The psychoneuroimmunology literature (e.g., Ader \& Felten, 2007) suggests that chronic stress reduces immune response. Compromised immune function tends to be most dramatic in people engaged in demanding activities due to unpredictable and uncontrollable events. Where purpose becomes relevant is that unpredictable and uncontrollable events ought to be maximally stressful for those behaving without the luxury of a central, motivating life aim. More efficient allocation of resources leads to greater persistence at difficult tasks; purpose leads to a surplus of resources to protect against threats to immune response. Based on a large body of research, we know that the most vulnerable family caregivers for older adult patients with dementia are those who tend to have less social support, more care demands, and fewer respites. These vulnerable caregivers exhibit diminished immune responses (Bauer, Vedhara, \& Perks, 2000; Redwine, Mills, \& Sada, 2004; Mills, Adler, \& Dimsdale, 2004). The sum of these findings suggests that chronic stress with no sense of control leads to a deteriorated immune functioning.

Caregivers are living with an incredibly important goal, to support their loved one throughout a terrible degenerating process. What we are suggesting is that purpose may contribute to the heterogeneous health outcomes of caregivers. Caregivers with the most compromised immune functioning may be those who accept the responsibilities, but do not recognize these efforts as part of purpose. When obligation, coercion, or guilt motivate caregiving, goal-related effort increases without translating into greater goalrelated joy, meaning, or progress (for reviews, see Little et al. 2007).

\section{Purpose in Emotion Research}

Another aspect of optimal resource allocation pertains to managing emotions. A person pursuing a purpose may often find 
obstacles to purpose-consistent behaviors. In those situations, remaining task focused, thinking about how to overcome the obstacles leads to successful pursuit of that purpose (S. C. Hayes, Luoma, Bond, Masuda, \& Lillis, 2006; Segerstrom, 2005); emotional instability interferes with goal pursuit (Berenbaum, Raghavan, Le, Vernon, \& Gomez, 2003; Johnson, 2005; Linehan, Bohus, $\&$ Lynch, 2007). The expression "grace under pressure" serves as the best exemplar of our point. Soldiers who remain calm during heated battles because they stay focused may be less likely to perish. Moreover, those same soldiers may be less affected by combat throughout life than soldiers without the capacity for optimal resource allocation.

\section{Can purpose buffer the impact of extreme stress in terms of resilience or speedier recovery?}

Recent empirical findings of positive outcomes after trauma experiences (Bonanno, Rennicke, \& Dekel, 2005; Wilson \& Murrell, 2004b) provides some clarity. The premise of this work is simple; a person's framework for understanding the world, other people, and the self are disrupted after traumatic experiences. As a result, people work to reconstruct their knowledge structures (e.g., sense of personal justice and illusion of personal control, JanoffBulman, 1992; Park, Cohen, \& Murch, 1997). People engage in a process of meaning-making to rebuild a coherent framework of who they are and how their lives operate in larger social systems. Contrary to decades of research suggesting that trauma survivors generally experience profound, lasting problems, Bonanno's work (e.g., Bonanno, Papa, Lalande, Zhang, \& Noll, 2005), in particular, provides evidence that resilience tends to be the most common trajectory in the aftermath of traumatic events.

Resilience is characterized by minor stress reactions followed by a quick return to normal functioning. This work leads to two logical questions; what are the critical ingredients of resilience and can these ingredients be instilled to increase the likelihood of adaptive outcomes?

Purpose serves as one, but not the only, potential explanatory variable of how a person can become resilient. Flexible use of various coping strategies to meet particular situational demands predicts resilience (Bonanno et al., 2005; Block \& Block, 1980). This finding diverges from variable-centric research that focuses on the greater utility of specific strategies (active vs. passive coping; e.g., Carver, Scheier, \& Weintraub, 1989; Penley, Tomaka, \& Wiebe, 2002; Suls \& Fletcher, 1985). People with access to a large set of self-regulatory tools, with an ability to flexibly apply them, are in an optimal position to navigate life challenges and sustain high levels of healthy functioning.

As mentioned previously, our conceptualization of purpose mandates flexibility and offers an overarching framework by which to predict and understand stress responses. Resilient stress responses observed by Bonanno and colleagues show the same adaptation that we hypothesize with purpose. Research focusing on posttraumatic growth provides additional insights into how people may react to and accommodate stress or trauma. In particular, research addressing the process of personal growth and its relevance to clinical outcomes and practice (e.g., Joseph \& Linley, 2006; Tedeschi \& Calhoun, 2004) offers potential mechanisms of stress response. While the personal growth research is consistent with purpose, the research fails to offer any testable hypotheses that distinguish trajectories of resilience, recovery, and functional impairments observed by Bonanno. The findings summarized in this section forms a bridge between the emotional response literature and the mental health literature. Furthermore, these points provide testable hypotheses that may readily accommodate our investigation into how purpose offers resilience and recovery.

\section{The Consequences of Purposeful Living}

Physical and mental health serve as outcomes directly influenced by purpose and as the fundamental aim of our synthesis. No direct empirical evidence ties our model of purpose to these outcomes. Instead, we discuss indirect evidence to support our model. Our interest in synthesizing various areas of research was to derive a parsimonious explanation of the underlying processes that influence health and well-being-both physical and mental. Purpose likely affects both areas positively and we expect that people who have purpose likely live healthier and happier lives.

Purpose ought to influence immune functioning, energy levels, and optimism. These expectations lead us to predict that purpose has direct effects on both physical and mental health (cf. selfconcordant strivings; Sheldon \& Kasser, 2001). Physical health benefits come not only from our expectations of better immune functioning but also from more active, healthier lifestyles.

Mental health benefits come from a "buffer" against life circumstances that often lead to mental health problems. The buffer may be mechanistically related to the motivating forces underlying purpose. A person dedicated to a purpose ought to be more prone to purpose consistent behaviors and less prone to those behaviors that are either irrelevant or counter to the purpose.

Drugs and alcohol might serve as a relaxation outlet for most people, but the abuse of those substances leads to substantial deterioration in goal directed appetitive behavior (e.g., Muraven, Collins, \& Nienhaus, 2002). Similarly, anxiety disorders, while beyond the control of the individual, are mediated by exposure; we expect purpose changes exposure through the mechanism of appetitive motivation. Finally, eating disorders tend to run counter to the notion of self-sustaining activity expected from purpose. Disturbances in eating would be expected but the pathological disturbances expected with the disorders ought to be remedied by help-seeking, self-help, self-control, or self-preservation. Moreover, if optimal resource allocation tends to be the underlying mechanism involved with purpose, then these disorders would be expected to be the least prevalent with people living with a purpose. Thus, we expect purpose to have a broad effect on both physical and mental health functioning.

The absence of disorder and disease does not inherently indicate that a person is psychologically healthy. That is, aside from acute stress, positive and negative experiences are often relatively independent (Cacioppo \& Berntson, 1994; Carver, Sutton, \& Scheier, 2000).

Health psychology conceptualizes function in two-dimensional space, with negative impairing problems as one dimension, and positive enriching experiences as another dimension. Thriving or optimal functioning would reflect low levels of negativity and high levels of positive functioning (Keyes, 2005; World Health Organization, 1946). Using this framework, it is worthwhile to consider a broader set of benefits that might be linked to purpose. One of our primary hypotheses is that acting in congruence toward one's 
purpose has a spillover effect into other life domains that only serve to enhance psychological, physical, and social well-being. Additionally, purpose leads to more behavioral consistency within and beyond occupational routines (e.g., engaging in activities to reduce work-family psychological conflict or enhance overall vitality and engagement in life).

Purposeful activities often require exercising character strengths such as courage and justice that result in challenges against other people or established norms. These stressful activities serve as substantial contributors to an engaging and meaningful life. In response to these more effortful activities, people living with a purpose may often prefer periods of restoration and leisure to build up their regulatory resources to return to a capacity that allows them behavioral continuity toward their purpose. This is not to say that for a person with purpose, the majority of activities in life are directly or indirectly related to their purpose. Rather, a purpose is intrinsically motivating and relatively effortless, and it is mood enhancing to engage in activities that are congruent with one's purpose. With notable exceptions, activities consistent with a purpose would be desirable, selected, and scheduled during autonomous periods. These activities would often have the secondary benefit of elevating the reward potential of subsequent events. These secondary benefits might be a function of purpose related activities being less likely to exhaust limited self-regulatory resources such as energy, attention, stamina, and executive functioning capacity (Muraven \& Baumeister, 2000). In fact, engaging in self-determined, satisfying experiences, such as living in accord with a purpose, might increase people's endurance during mentally and physically challenging activities and sustain their vitality in the aftermath (e.g., Moller, Deci, \& Ryan, 2006; Muraven, Gagn, \& Rosman, 2008).

\section{Essential Elements of Purpose}

There are several required elements for purpose-elements that form the basis of our definition. First, purpose stimulates behavioral consistency; serving as the motivating force to overcome obstacles, to seek alternative means, and to maintain focus on the goal, in spite of changing environmental conditions. People who live with a purpose might be more consistent in their behaviorsboth public and private. Also, behaviors ought to be resilient to changing environmental conditions or obstacles (cf. perseverance against barriers Segerstrom, 2005). Second, purpose generates appetitively (i.e., approach oriented) motivated behaviors. Greater appetitive motivation suggests a stronger purpose. Third, purpose stimulates psychological flexibility. Purpose leads a person to be more flexible in light of changing demands, obstacles, and opportunities. The literature concerning posttraumatic growth and resilience illustrated this requirement. People find ways to avoid the hardships by being able to flexibly manage their environment (both physical and psychological). By avoiding these hardships, people experience fewer psychological and physical problems that may befall people without purpose. Fourth, purpose fosters efficient resource allocation and leads to more productive cognitive, behavioral, and physiological activity.

The fifth and final essential element-perhaps the most fundamental aspect of purpose-is higher-level cognitive processing. That is, a purpose involves a higher level of cognitive processing by the cerebral cortex and not driven solely by lower-level cogni- tive processes in the midbrain or lower. The reason we emphasize this point is to differentiate purpose from primal motivations such as food, safety, and pleasure. Most organisms possess primal motivations (such as those defined by the pleasure principle or needs Freud, 1933; Murray, 1938) that get typically described as universal traits. If these motivations are universal then there cannot be any individual differences that lead some to not have those essential needs and others to have more essential needs. Our definition of purpose would eliminate the opportunity for organisms who do not possess these higher-order cognitive processes to have a purpose. Similarly, the requirement for a purpose to be a higher-order cognitive process eliminates the ability for critics to argue that a person living a hedonistic existence could be construed as a person living with a purpose. It is true that the person is living with an appetitive, goal-directed motivation, but the fact that the motivation stems from a more primitive drive eliminates it from fulfilling our essential elements of purpose.

We suspect that people meeting the boundary conditions, but lacking purpose live less satisfying lives than those who fail to meet the boundary conditions. The absence of purpose in the lives of able individuals might provide a partial explanation for substantial elevations in the prevalence of depression, feelings of emptiness, and suicide in the elderly (Richman, 1993; Ruckenbauer, Yazdani, \& Ravaglia, 2007). Just because a person is able to form a purpose does not mandate that a purpose will be formed and sought after; recognizing this absence of purpose can lead to suffering. In contrast, people unaware of the nature of purposeful living might be immune to this form of suffering.

These requirements might be thought of as necessary ingredients, but none sufficient to create or indicate the presence of purpose. That is, if any essential element is missing then purpose cannot be present; if all four requirements are met, it does not necessitate that purpose is indeed present.

\section{Summary and Future Directions}

Our aim was to develop a comprehensive view of a single, causal agent that might account for a loosely aligned set of outcomes. That single agent we called purpose. We defined what purpose was and how it might be differentiated from other theoretical constructs. In addition, we addressed expected criticisms about the theoretical similarity with existing models such as TMT and SDT and hold that what we propose is not only different but also integrative within those two theoretical systems. Our work in this area has just begun. Collaborations with experts from areas within and outside psychology will only help to test our theory and other related theories to bring about a better understanding of human agency. Those collaborations might be enhanced by starting with a few critical hypotheses that hold the fabric of these theories together. In their classic book, Goldstein, Heller, and Sechrest (1966) listed many testable hypotheses that were critical to the study of psychotherapy. In that vein, we propose to do the same. Our aim is to stimulate research in this area and to help rule out incomplete models. Also, we aim to stimulate research that may help refine and synthesize the growing body of literature that documents the effects of personal initiative, goal-directed behavior, individual perseverance, personal strivings, and need for cognition, among others. The following list offers a set of critical questions that serve to refute our model of purposeful living. 
Purpose leads to behavioral consistency and thus leads to the following hypotheses: (a) random sampling in naturalistic settings ought to show that people living purposeful lives tend behave consistent with a purpose; (b) purpose influences both vocational and avocational decisions throughout life; and (c) the creation of goals consistent with ones purpose may be critical to differentiating between real purpose and illusory purpose.

Purpose creates more psychological flexibility leading to the following hypotheses: (a) people pursuing a purpose ought to be less susceptible to avoidance behaviors such as procrastination compared to those who are merely goal-directed; (b) purpose motivates people to persist rather than quit in face of difficult situations; and (c) purpose ought to differentiate those who respond to traumatic events in a flexible manner from those who respond in ways that may lead to psychological distress or functional impairment.

Purpose leads to greater efficiency in resource allocation leading to the following hypotheses: (a) purpose enhances rebound capacity through more efficient resource allocation; (b) the refractory period following any stressful event will be shorter for those with purpose; and, (c) people who live with a purpose will be less prone to illness and report fewer symptoms even when ill.

Purpose leads to lower stress levels and greater satisfaction with life, leading to the following hypotheses: (a) stress and satisfaction will be dictated by the level of congruence between the purpose and the opportunity to fulfill that purpose; (b) purpose buffers against psychological or physical suffering during uncontrollable hardships; and (c) purposeful living produces longer-term, durable benefits as compared with nonpurposeful living.

Purpose has clearly definable characteristics leading to the following hypotheses: (a) general intelligence, introspective abilities, perceived competence, and perceived self-determination affect the likelihood that people will have a clearly defined purpose; (b) social values affect the difficulty of achieving purpose-motivated intermediate goals; and (c) people who are aware of their abilities and can form a purpose, will suffer more than those who are either unable to form or lack the insight of the importance of purpose.

Each of the above hypotheses represents a critical test of our proposed model for the measurement, formation, maintenance, or impact of purpose in life. They represent critical tests of our assertions and failure to "pass" these hurdles ought to call into question our model. We feel that hypotheses aimed to support proposed theories only lead to scientifically bankrupt models; fortunately, we are not alone in this perspective (cf. Chamberlin, 1890). Our future work in this area aims to address each of these questions in both experimental and observational settings. In summary, purpose provides a framework for both researchers to understand how people live and individuals to guide how to live.

\section{References}

Ader, R., \& Felten, D. (2007). Psychoneuroimmunology (4th ed.). Burlington, MA: Elsevier Academic Press.

Allen, K., Shykoff, B. E., \& Izzo, J., Jr. (2001). Pet ownership, but not ace inhibitor therapy, blunts home blood pressure responses to mental stress. Hypertension, 38, 815.

Assor, A., Roth, G., \& Deci, E. L. (2004). The emotional costs of parents' conditional regard: A self-determination theory analysis. Journal of Personality, 72, 47-88.
Bargh, J. A., \& Barndollar, K. (1996). Automaticity in action: The unconscious as repository of chronic goals and motives. In P. Gollwitzer \& J. Bargh (Eds.), The psychology of action: Linking cognition and motivation to behavior (pp. 457-481). New York: Guilford Press.

Baron, J., \& Kemp, S. (2004). Support for trade restrictions, attitudes, and understanding of comparative advantage. Journal of Economic Psychology, 25, 565-580.

Bauer, M. E., Vedhara, K., \& Perks, P. (2000). Chronic stress in caregivers of dementia patients is associated with reduced lymphocyte sensitivity to glucocorticoids. Journal of Neuroimmunology, 103, 84-92.

Berenbaum, H., Raghavan, C., Le, H., Vernon, L., \& Gomez, J. (2003). A taxonomy of emotional disturbances. Clinical Psychology: Science and Practice, 10, 206-226.

Block, J. H., \& Block, J. (1980). The role of ego-control and ego-resiliency in the organization of behavior. In W. A. Collins (Ed.), Development of cognition, affect, and social relations: The Minnesota symposia on child psychology (Vol. 13, pp. 39-101). Hillsdale, NJ: Erlbaum.

Bonanno, G. A., Papa, A., Lalande, K., Zhang, N., \& Noll, J. G. (2005). Grief processing and deliberate grief avoidance: A prospective comparison of bereaved spouses and parents in the United States and the people's republic of china. Journal of Consulting and Clinical Psychology, 73, 86-98.

Bonanno, G. A., Rennicke, C., \& Dekel, S. (2005). Self-enhancement among high-exposure survivors of the September 11th terrorist attack: Resilience or social maladjustment? Journal of Personality and Social Psychology, 88, 984-998.

Brown, K., Ryan, R., \& Creswell, J. (2007). Mindfulness: Theoretical foundations and evidence for its salutary effects. Psychological Inquiry, 18, 1-26.

Brown, S., Nesse, R., Vinokur, A., \& Smith, D. (2003). Providing social support may be more beneficial than receiving it: Results from a prospective study of mortality. Psychological Science, 14, 320-327.

Burton, K. D., Lydon, J. E., D’Alessandro, D. U., \& Koestner, R. (2006). The differential effects of intrinsic and identified motivation on wellbeing and performance: Prospective, experimental, and implicit approaches to self-determination theory. Journal of Personality and Social Psychology, 91, 750-762.

Cacioppo, J., \& Berntson, G. (1994). Relationship between attitudes and evaluative space: A critical review, with emphasis on the separability of positive and negative substrates. Psychological Bulletin, 115, 401-423.

Carver, C. S., \& Scheier, M. F. (1998). On the self-regulation of behavior. New York: Cambridge University Press.

Carver, C. S., \& Scheier, M. F. (2002). Control processes and selforganization as complementary principles underlying behavior. Personality and Social Psychology Review, 6, 304-315.

Carver, C. S., Scheier, M. F., \& Weintraub, J. K. (1989). Assessing coping strategies: A theoretically based approach. Journal of Personality and Social Psychology, 56, 267-283.

Carver, C. S., Sutton, S. K., \& Scheier, M. F. (2000). Action, emotion, and personality: Emerging conceptual integration. Personality and Social Psychology Bulletin, 26, 741-751.

Carver, C. S., \& White, T. L. (1994). Behavioral inhibition, behavioral activation, and affective responses to impending reward and punishment: The bis/bas scales. Journal of Personality and Social Psychology, 67, 319-333.

Chamberlin, T. (1890). The method of multiple working hypotheses. Science, 15, 92-96.

Cichon, M. (1997). Evolution of longevity through optimal resource allocation. Proceedings: Biological Sciences, 264, 1383-1388.

Cichon, M. (2001). Diversity of age-specific reproductive rates may result from ageing and optimal resource allocation. Journal of Evolutionary Biology, 14, 180-185.

Cohen, S., \& Pressman, S. D. (2006). Positive affect and health. Current Directions in Psychological Science, 15, 122-125. 
Côté, S., \& Moskowitz, D. (1998). On the dynamic covariation between interpersonal behavior and affect: Prediction from neuroticism, extraversion, and agreeableness. Journal of Personality and Social Psychology, 75, 1032-1046.

deCharms, R. (1968). Personal causation. New York: Academic Press.

Deci, E., \& Ryan, R. (2000). The "what" and "why" of goal pursuits: Human needs and the self-determination of behavior. Psychological Inquiry, 11, 227-268.

Donahue, E. M., Robins, R. W., Roberts, B. W., \& John, O. P. (1993). The divided self: Concurrent and longitudinal effects of psychological adjustment and social roles on self-concept differentiation. Journal of Personality and Social Psychology, 64, 834-846.

Duckworth, A. L., Peterson, C., Matthews, M. D., \& Kelly, D. R. (2007). Grit: Perseverance and passion for long-term goals. Journal of Personality and Social Psychology, 92, 1087-1101.

Elliot, A. (2006). The hierarchical model of approach-avoidance motivation. Motivation and Emotion, 30, 111-116.

Elliot, A., Gable, S., \& Mapes, R. (2006). Approach and avoidance motivation in the social domain. Personality and Social Psychology Bulletin, 32, 378-391.

Emmons, R. (1999). The psychology of ultimate concerns: Motivation and spirituality in personality. New York: Guilford Press.

Emmons, R. A. (1991). Personal strivings, daily life events, and psychological and physical well-being. Journal of Personality, 59, 453-472.

Ferguson, M. J., \& Bargh, J. A. (2004). Liking is for doing: The effects of goal pursuit on automatic evaluation. Journal of Personality and Social Psychology, 87, 557-572.

Frankl, V. (1963). Man's search for meaning: An introduction to logotherapy. New York: Washington Square Press.

Freud, S. (1933). New introductory lectures on psychoanalysis. New York: Norton.

Gagn, M. (2003). The role of autonomy support and autonomy orientation in prosocial behavior engagement. Motivation and Emotion, 27, 199223.

Goldstein, A., Heller, K., \& Sechrest, L. (1966). Psychotherapy and the psychology of behavior change. New York: Wiley and Sons.

Gollwitzer, P. (1999). Implementation intentions: Strong effects for simple plans. American Psychologist, 54, 493-503.

Gray, J. (1995). The contents of consciousness: A neuropsychological conjecture. Behavioral and Brain Sciences, 18, 659-722.

Greenberg, J., Pyszczynski, T., \& Solomon, S. (1986). Public self and private self. In R. Baumeister (Ed.), The causes and consequences of a need for self-esteem: A terror management theory (pp. 189-212). New York: Springer-Verlag.

Grolnick, W. S., \& Ryan, R. M. (1987). Autonomy in children's learning: An experimental and individual difference investigation. Journal of Personality and Social Psychology, 52, 890-898.

Hayes, S., Follette, V., \& Linehan, M. (2004). Mindfulness and acceptance: Expanding the cognitive behavioral tradition. New York: Guilford Press.

Hayes, S. C., Luoma, J. B., Bond, F. W., Masuda, A., \& Lillis, J. (2006). Acceptance and commitment therapy: Model, processes and outcomes. Behaviour Research and Therapy, 44, 1-25.

Hicks, J., \& King, L. (2008). Religious commitment and positive mood as information about meaning in life. Journal of Research in Personality, 42, 43-57.

House, J., Landis, K., \& Umberson, D. (1988). Social relationships and health. Science, 241, 540-545.

Jackendoff, R. (1987). Consciousness and the computational mind. Cambridge, MA: MIT Press.

Janoff-Bulman, R. (1992). Shattered assumptions: Towards a new psychology of trauma. New York: Free Press.

Johnson, S. L. (2005). Mania and dysregulation in goal pursuit. Clinical Psychology Review, 25, 241-262.
Joseph, S., \& Linley, P. A. (2006). Growth following adversity: Theoretical perspectives and implications for clinical practice. Clinical Psychology Review, 26, 1041-1053.

Kasser, T., \& Ryan, R. M. (1993). A dark side of the American dream: Correlates of financial success as a central life aspiration. Journal of Personality and Social Psychology, 65, 410-422.

Keyes, C. L. M. (2005). Mental illness and/or mental health? investigating axioms of the complete state model of health. Journal of Consulting and Clinical Psychology, 73, 539-548.

King, L. A., Hicks, J. A., Krull, J., \& Del Gaiso, A. K. (2006). Positive affect and the experience of meaning in life. Journal of Personality and Social Psychology, 90, 179-196.

Klinger, E. (1977). Meaning and void. Minneapolis, MN: University of Minnesota Press.

Koestner, R., Lekes, N., Powers, T., \& Chicoine, E. (2002). Attaining personal goals: Self-concordance plus implementation intentions equals success. Journal of Personality and Social Psychology, 83, 231-244.

Kruglanski, A. W., Shah, J. Y., Fishbach, A., Friedman, R., Chun, W., \& Sleeth-Keppler, D. (2002). A theory of goal-systems. In M. Zanna (Ed.), Advances in experimental social psychology (Vol. 34, pp. 331-378). New York: Academic Press.

Linehan, M., Bohus, M., \& Lynch, T. (2007). Handbook of emotion regulation. In J. Gross (Ed.), Dialectical behavior therapy for pervasive emotion dysregulation: Theoretical and practical underpinnings (pp. 581-605). New York: Guilford Press.

Little, B., Salemla-Aro, K., \& Phillips, S. (2007). Personal project pursuit: Goals, action and human flourishing. Mahwah, NJ: Erlbaum.

Lyubomirsky, S., Sheldon, K. M., \& Schkade, D. (2005). Pursuing happiness: The architecture of sustainable change. Review of General Psychology, 9, 111-131.

McAdams, D. (2001). The psychology of life stories. Review of General Psychology, 5, 100-122.

McGregor, I., \& Little, B. R. (1998). Personal projects, happiness, and meaning: On doing well and being yourself. Journal of Personality and Social Psychology, 74, 494-512.

Mills, P., Adler, K., \& Dimsdale, J. (2004). Vulnerable caregivers of Alzheimer disease patients have a deficit in beta-sub-2-adrenergic receptor sensitivity and density. American Journal of Geriatric Psychiatry, 12, 281-286.

Moller, A. C., Deci, E. L., \& Ryan, R. M. (2006). Choice and egodepletion: The moderating role of autonomy. Personal and Social Psychology Bulletin, 32, 1024-1036.

Muraven, M., \& Baumeister, R. F. (1997). Suicide, sex, terror, paralysis, and other pitfalls of reductionist self-preservation theory. Psychological Inquiry, 8, 36-40.

Muraven, M., \& Baumeister, R. F. (2000). Self-regulation and depletion of limited resources: Does self-control resemble a muscle? Psychological Bulletin, 126, 247-259.

Muraven, M., Collins, R., \& Nienhaus, K. (2002). Self-control and alcohol restraint: An initial application of the self-control strength model. Psychology of Addictive Behaviors, 16, 113-120.

Muraven, M., Gagn, M., \& Rosman, H. (2008). Helpful self-control: Autonomy support, vitality, and depletion. Journal of Experimental Social Psychology, 44, 573-585.

Murray, H. (1938). Explorations in personality. New York: Oxford University Press.

Nelson, K., \& Fivush, R. (2004). The emergence of autobiographical memory: A social cultural developmental theory. Psychological Review, 111, 486-511.

Niemic, C., Brown, K., Kashdan, T., Breen, W., Levesque-Bristol, C., \& Ryan, R. (n.d.). Being present when facing death: The role of mindfulness in terror management. Manuscript submitted for publication.

Novick, M., \& Ellis, D. (1977). Equal opportunity in educational and employment selection. American Psychologist, 32, 306-320. 
Oman, D., Thoresen, C., \& McMahon, K. (1999). Volunteerism and mortality among the community-dwelling elderly. Journal of Health Psychology, 4, 301-316.

Park, C., Cohen, L., \& Murch, R. (1997). Assessment and prediction of stress-related growth. Journal of Personality, 64, 71-105.

Penley, J. A., Tomaka, J., \& Wiebe, J. S. (2002). The association of coping to physical and psychological health outcomes: A meta-analytic review. Journal of Behavioral Medicine, 25, 551-603.

Pyszczynski, T., Greenberg, J., Solomon, S., Arndt, J., \& Schimel, J. (2004). Why do people need self-esteem? A theoretical and empirical review. Psychological bulletin, 130, 435-468.

Redwine, L., Mills, P., \& Sada, M. (2004). Differential immune cell chemotaxis responses to acute psychological stress in Alzheimer caregivers compared to non-caregiver controls. Psychosomatic Medicine, 66, $770-775$.

Ricardo, D. (1817). On the principles of political economy and taxation. London: John Murray.

Richman, J. (1993). Preventing elderly suicide: Overcoming personal despair, professional neglect, and social bias. New York: Springer.

Rogers, C. (1951). Client-centered therapy; its current practice, implications, and theory. Boston: Houghton Mifflin.

Ruckenbauer, G., Yazdani, F., \& Ravaglia, G. (2007). Suicide in old age: Illness or autonomous decision of the will? Archives of Gerontology and Geriatrics, 44Suppl, 1, 355-358.

Ryan, R. M., \& Deci, E. L. (2004). Avoiding death or engaging life as accounts of meaning and culture: A comment on Pyszczynski, Greenberg, Solomon, Arndt, and Schimel. Psychological Bulletin, 130, 473477.

Segerstrom, S. C. (2005). Optimism and immunity: Do positive thoughts always lead to positive effects? Brain, Behavior, and Immunity, 19, 195-200.

Shafir, E., Osherson, D., \& Smith, E. (1993). The advantage model: A comparative theory of evaluation and choice under risk. Organizational Behavior and Human Decision Processes, 55, 325-378.

Sheldon, K. (2002). Handbook of self-determination research. In E. D. R. Ryan (Ed.), The self-concordance model of healthy goal-striving: When personal goals correctly represent the person (pp. 65-86). Rochester, NY: University of Rochester Press.

Sheldon, K., \& Elliot, A. (1999). Goal striving, need-satisfaction, and longitudinal well-being: The self-concordance model. Journal of Personality and Social Psychology, 76, 482-497.

Sheldon, K., \& Kasser, T. (1995). Coherence and congruence: Two aspects of personality integration. Journal of Personality and Social Psychology, 68, 531-543.

Sheldon, K., \& Kasser, T. (1998). Pursuing personal goals: Skills enable progress but not all progress is beneficial. Personality and Social Psychology Bulletin, 24, 1319-1331.

Sheldon, K., \& Kasser, T. (2001). Getting older, getting better? Personal strivings and psychological maturity across the life span. Developmental Psychology, 37, 491-501.

Sheldon, K., \& Krieger, L. (2007). Understanding the negative effects of legal education on law students: A longitudinal test of self-determination theory. Personality and Social Psychology Bulletin, 33, 883-897.
Sheldon, K., Ryan, R., Deci, E., \& Kasser, T. (2004). The independent effects of goal contents and motives on well-being: It's both what you pursue and why you pursue it. Personality and Social Psychology Bulletin, 30, 475-486.

Snyder, C. (1997). Control and the application of Occam's razor to terror management theory. Psychological Inquiry, 8, 48-49.

Solomon, S., Greenberg, J., \& Pyszczynski, T. (1991). Advances in experimental social psychology. In M. P. Zanna (Ed.), A terror management theory of social behavior: The psychological functions of self esteem and cultural worldviews (Vol. 24, pp. 91-159). San Diego, CA: Academic Press.

Steger, M., Frazier, P., Oishi, S., \& Kaler, M. (2006). The meaning in life questionnaire: Assessing the presence of and search for meaning in life. Journal of Counseling Psychology, 53, 80-93.

Strawbridge, W. J., Cohen, R. D., Shema, S. J., \& Kaplan, G. A. (1997). Frequent attendance at religious services and mortality over 28 years. American Journal of Public Health, 87, 957-961.

Suls, J., \& Fletcher, B. (1985). Self-attention, life stress, and illness: A prospective study. Psychosomatic Medicine, 47, 469-481.

Tanaka, H. (1989). Power as maximizing behavior. Behavioral Science, 34, 199-206.

Tedeschi, R., \& Calhoun, L. (2004). Posttraumatic growth: Conceptual foundations and empirical evidence. Psychological Inquiry, 15, 1-18.

Triandis, H. (1989). The self and social behavior in differing cultural contexts. Psychological Review, 96, 506-520.

Vallerand, R. J., Deci, E. L., \& Ryan, R. M. (1987). Intrinsic motivation in sport. Exercise and Sport Sciences Reviews, 15, 389-425.

Warren, R. (2002). The purpose driven life: What on earth am I here for? Grand Rapids, MI: Zondervan.

Wilson, K., \& Murrell, A. (2004a). Mindfulness and acceptance: Expanding the cognitive-behavioral tradition. In S. C. Hayes, V. M. Follette, \& M. Linehan (Eds.), Values work in acceptance and commitment therapy: Setting a course for behavioral treatment (pp. 120-151). New York: Guilford Press.

Wilson, K., \& Murrell, A. (2004b). Values work in acceptance and commitment therapy: Setting a course for behavioral treatment. In S. Hayes, V. Follette, \& M. Linehan (Eds.), Mindfulness and acceptance: Expanding the cognitive-behavioral tradition (pp. 120-151). New York: Guilford Press

Wong, P., \& Fry, P. S. (Eds.). (1998). The human quest for meaning: A handbook of psychological research and clinical application. Mahwah, NJ: Erlbaum.

World Health Organization. (1946). Constitution of the World Health Organization. (Tech. Rep.). Geneva: World Health Organization.

Zhang, Y., Fishbach, A., \& Kruglanski, A. W. (2007). The dilution model: How additional goals undermine the perceived instrumentality of a shared path. Journal of Personality and Social Psychology, 92, 389401

Received June 6, 2008

Revision received December 8, 2008 Accepted November 1, 2008 